\section{Autonomous language learning in Iranian context: To what extent do students take responsibility for their learning?}

\author{
Ahmadi, Razieyeh $\bowtie$ \\ University of Guilan, Iran (Raziahmadi22@yahoo.com) \\ Mahdavi-Zafarghandi, Amir \\ University of Guilan, Iran (Mahdavi1339@gmail.com)
}

Received: 5 November 2012

Available Online: 18 March 2013

Accepted: 14 February 2013

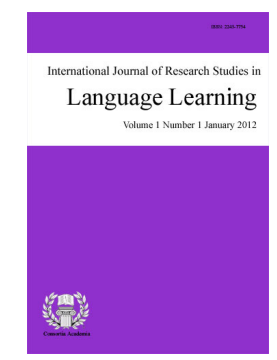

ISSN: $2243-7754$ Online ISSN: 2243-7762

OPEN ACCESS

\title{
Abstract
}

This study was conducted to investigate the views of Iranian university students regarding responsibility and decision making ability related to autonomous language learning and the practice of autonomous activities inside and outside the classroom. The study also investigated whether or not male and female students differ regarding responsibility and ability views. In order to reach these aims, a questionnaire by Chan, Humphreys, and Spratt (2002) was used and distributed among 133 Law major students at the Law Department of University of Guilan. The results indicated that although students considered their ability level as average, they believed that the responsibility of managing and planning aspects of their learning should be held to their teachers. The findings also showed that gender did not play any role in students' views regarding their responsibility and ability. The results of this study have some implications for course designers, material developers, and teachers to be informed of students' responsibility views. They can take this information into account before promoting the learner autonomy.

Keywords: autonomy in language learning; learner responsibility; autonomous activities; decision making ability; gender and autonomy 


\section{Autonomous language learning in Iranian context: To what extent do students take responsibility for their learning?}

\section{Introduction}

The interest in the role of the learner in second language teaching dates back to 1960s and autonomy is one of the concepts that has been borrowed from the fields of psychology and social theory to define the role of the learner in the language learning process (Benson, 2009), the idea of autonomy attracted a lot of attention in recent years. The most commonly cited definition was proposed by Holec (1981) autonomy is "the ability to take charge of one's own learning" and "ability and capacity that needs to be acquired" rather than a process (p. 3). Autonomy is not synonymous with freedom and students should accept the rules and conventions in the classroom, the authority of the teacher, and rights of their classmates (Dickinson, 1994).

As Little (2004) suggested, learner autonomy has several factors. The first is that it is based on learner involvement, referring to active participation of learners in the learning process, i.e. autonomous language learners need to have the freedom of choice of what and how to learn and they should take the responsibility of their own learning (Farrell \& Jacobs, 2010). The second factor is learner reflection, which includes planning, monitoring, and evaluating of learning by students (Little, 2004). One of the vital factors that relates to students' reflection is self-assessment. This way, students build an inner criterion to measure their learning and judge their weaknesses and strengths. The third factor is the use of the target language as the only medium of communication in all types of interaction in the classroom.

Learner autonomy is a demanding notion in the Asian contexts, because it challenges the traditional role of the teacher as the authority figure and initiator of all the activities in the classroom. However, in Iran the educational system tends to "turn students into the mere listener, viewer, and observant" (Pishghadam \& Naji Meidani, 2011), because teachers' talk is dominant and students are passive recipients of knowledge in the classroom. One of the difficulties in the application of autonomy in Iranian society relates to the cultural norms, based on Hofsted (1986)'s categorization of cultural norms, Iranian culture can be classified as collectivists. Some of the characteristics of collectivist societies are "teacher-centered education, the purposes of education is learning how to do, harmony should always be maintained, and relationship prevails over task" (Hofsted, 2011).

So, before any application, there is a need for assessing students' views and perceptions towards autonomous language learning in an the Iranian context. The purpose of this research is to gain a greater understanding of Iranian learners' perceptions towards autonomy through investigating their views of responsibility, decision making ability, and activity types. The following issues were addressed in this study:

a. What are Iranian students' views of their responsibility and their teachers' responsibility in learning language autonomously?

b. What are Iranian students' views of their decision making ability to learn English language autonomously?

c. What different activities are Iranian students engaged in learning the English language autonomously?

d. Are there any differences in Iranian students' views of their responsibility and ability in learning English regarding gender? 


\section{Literature review}

\subsection{What is Autonomy?}

Autonomy is a complex construct and viewed differently by different scholars, Benson (2006) considered it as an ability and attitude, or for Dickinson (1995) autonomy is an attitude rather than a methodology. According to Dickinson (1994) autonomy is a "goal of education" (p. 5), and the work towards autonomy is teacher-centered at the initial stages, in this process students and teachers work together cooperatively and as a result students, take more responsibility at the later stages of the language learning experience. Smith (2002) described two types of autonomy: Strong version and weak version. In strong version, the teacher gives the initiation of activities and the responsibility of decision making to the students. Students might be engaged in "taking charge of classroom-based learning" (p. 6), in the following areas: "Determining the objectives, defining the content and the progressions; selecting methods and techniques to be used; monitoring the procedure of acquisition" (Smith, 2002, p. 6). This strong version is similar to the proactive type of autonomy proposed by Littlewood (1999) which, for many scholars and researchers in this field, is the only type of autonomy. Proactive type of autonomy is common in the Western educational system, and proactive autonomous students initiate the activities and select objectives and materials.

According to Smith (2002), the weak version of autonomy is associated with technological and strategic based language learning. Smith (2002) argued this version of autonomy "poses little threat to traditional pedagogies of dependence" and which can be "easily packages" and "sold in various contexts" (p. 8). The role of the teacher as the knower and an expert is less affected within this type of approach and it deals with technology based language learning, self-access language learning in self-access centers, and strategy training courses. In his classification of autonomy Littlewood (1999), proposed another type of autonomy, "reactive autonomy" in which all the directions set by the teacher and learners use all sources "autonomously" to reach the goals (p. 76). Littlewood used Flannery (1994) and argued that the reactive type of autonomy is similar to cooperative learning strategies in which the teacher selects methods and sets the objectives. Littlewood (1999) also indicated this type of autonomy "complements rather than challenges the traditional structure of knowledge and authority" (p. 76). Benson (2001) also supports these views maintaining that, proactive autonomy is "the control over the methods and content of learning" but reactive autonomy involves "control over methods alone" (p. 99).

The concept of autonomy does not mean working in isolation (Little, 2007) and the result of preparing learners for autonomy results in a teaching/learning process in which responsibility is shared between learners and teachers. Many scholars (e.g. Dickinson, 1994; Littlewood, 1996; Little, 1999) considered autonomy as an educational goal which is applicable in different settings and not limited to the Western educational system but the development of autonomy among students is a process that "needs a teacher for a variety of reasons", (Aoki, 1999, p. 151). According to Aoki (1999), teachers in an autonomous classroom setting possess certain type of roles. The first is that of, "giving authority" to the students' feeling. Teachers should help students to feel that they are autonomous. The second is that, the development of autonomy requires practice. This means that students should be involved in the decision making process in their learning. The third is that, the development of autonomy needs an interaction between the teacher and the learner in the classroom where it differs from their traditional relationship in which the teacher is the sole decision maker in the classroom. The fourth is that, the teachers' "acknowledgment of the student" role as an individual in the language learning process, and finally, it is that of teachers' support for students practicing autonomy.

\subsection{Researchers around the world}

One of the seminal studies on learners' views and understandings of autonomy was conducted by Chan, Humphreys, and Spratt (2002). They investigated the students' views towards their responsibility, those of their teachers', their confidence in their ability to operate autonomously, and their assessment of their level of 
Ahmadi, R. \& Mahdavi-Zafarghandi, A.

motivation to learn English. The study also examined the actual practice of autonomy both inside and outside the classroom. The participants were 508 male and female students taking English courses in Polytechnic Hong Kong University. They employed questionnaire and interview to gather the data. The findings of the study revealed that students did not have a good understanding of their own responsibilities and abilities and they considered them to be teachers' responsibility. The results also showed that, in order to develop autonomy by the use of outside class activities, it is better to use those activities that students, have already been engaged in. One of the variables in the study was motivation which showed that there was a strong relationship between higher levels of motivation and greater engagement in outside class activities.

There is a growing body of research studies on autonomous language learning in Iran, each of which investigated different aspects of the concept of autonomy or the effect of different variables on it; for example, Zohrabi (2011) used a reciprocal approach to enhance language learning autonomy among 63 students in English for General Purposes (EGP) course. The researcher used different instruments; informal needs analysis, informal discussions with students, field notes, continuous observation of students, journals, and diaries to give freedom and autonomy to the students to learn English based on their needs and aims. Zohrabi's (2011) study was an example of the employment of autonomous language learning in Iranian tertiary settings. Results showed that the students in an autonomous classroom setting can learn the language based on their needs and aims.

In another notable study, Kashefian-Naini (2002) investigated 168 English learners' beliefs towards autonomous language learning. In the study, which was conducted at Shiraz University, the researcher used Cotterall's (1995) questionnaire and employed factor analysis. The findings revealed the existence of the following factors in Iranian educational setting: Learner independence, dependence on teacher, learner confidence, attitudes towards language learning, and self-assessment.

There is no study regarding whether or not students are taking responsibility for language learning, their decision making ability, and their practice of autonomous activities inside and outside class activities. So this current research study could bridge this gap by investigating the students' views towards these areas to measure their understanding of autonomous language learning.

\section{Methodology}

\subsection{Participants}

The participants of this study were selected through purposive sampling because this study focused on 133 undergraduate, male and female law students from the University of Guilan between the ages of 18 and 25 from the Law Department at the University of Guilan.

\subsection{Instrument}

A paper and pencil questionnaire comprising three sections (responsibility, ability, and autonomous activities inside and outside of the class) was adapted from Chan et al. (2002). It was translated into Persian language (Farsi) to avoid any misunderstanding and was revised two times by the two experts at the University of Guilan to ensure its validity. The final version was used in a pilot study. Two items were revised based on the comments received from item analysis carried on the results of the pilot study. For the reliability of the questionnaire, the Cronbach-alpha value was calculated and the internal consistency of the instrument found to be 0.94 which indicates a high level of reliability.

\subsection{Data Collection Procedure}

The questionnaire was given to students attending English for specific purpose courses in the Law Department of University of Guilan. It was administered at the beginning of the second semester of academic 
Autonomous language learning: To what extent do students take responsibility for their learning?

year of 2012-2013. It took about 30 minutes to be completed and the participants were ensured that their anonymity was guaranteed and their responses to the questionnaire would not affect their grades.

\subsection{Data Analysis}

The statistical analyses were conducted by using the statistical packages for the social sciences (SPSS) version 19.0 software program. In the present study, descriptive statistics (percentages and frequencies) were calculated. In addition, chi-square test of independence was applied to see whether or not there is a significant relationship between Iranian students' views of responsibility and ability in learning English and their gender. The relationship was regarded statistically significant at $.05 \mathrm{P}$ value. The descriptive statistics were also used to measure the frequency of inside and outside classroom autonomy.

\section{Results and Discussion}

\subsection{Iranian students' views on responsibility}

The first section of the Learner Autonomy Questionnaire assessed the students' views of their responsibility and their teachers' responsibility to learn the language autonomously. The questionnaire covered 59 items and the participants ranked their responses on a five-point Likert scale that goes from 0 (not at all) to 5 (completely). Table 1 presents the percentages of answers related to each item. For the ease of interpretation, the "not at all" and "a little" were considered in a negative category whereas "mainly" and "completely" categories have been combined into one positive category.

The results showed that the students expressed a notion of shared responsibility concerning items, 1, 3, 11, and 12. For example, for item 1 (making sure you make progress during lessons), $54.1 \%$ of the respondents said that they have "mainly/completely" responsibility for making sure that they make progress during lessons. This means that the majority of the students shared the responsibility of checking their progress with their teachers. Similarly, for item 3 (stimulating interest in learning English) and item 11 (evaluating learning) and item 12 (deciding what to learn outside the class) students shared the responsibility of evaluating, deciding on what to learn outside the class, and stimulating their interest in learning with their teachers.

Knowing students share these responsibilities with their teacher might be considered a positive outcome because it shows that they are aware of some of their responsibilities in the learning process. In fact the development of autonomous behavior among students aware of the notion of sharing responsibility is not demanding for teachers, because they are ready to accept some of the responsibilities in the language learning process.

For items 6, 7, and 10 the percentages of responses showed that students gave more responsibility to their teacher. For example, concerning item 7 (deciding what to learn next in English lessons), 50.4\% of the respondents said that they gave the responsibility to their teachers and only $36.8 \%$ of the respondents said that students have the responsibility. Similarly, for items 6, 8, and 10 the students assigned to their teachers the responsibility of deciding the objectives of English course and choosing what activities and materials to use to learn English in their English lessons.

The participants of this study considered themselves responsible for the activities expressed in items 2, 4, 5, 9, and 13. These items refer to (making progress outside the class, identifying weaknesses, working harder, deciding how long to spend on each activity, and deciding what to learn outside the class). These items are directly related to the personal experience of students in learning English. Besides these activities affect their performance on the test and their overall progress in language learning, for example, for the item "deciding what to learn outside the class", students normally do whatever they enjoy outside the class to learn English language, and this is a part of their language learning experience which influences their success. 
The findings of this study revealed that the participants were ready to accept responsibility in some aspects of their learning, but they still need teachers' help and support for the other aspects such as managing and planning the course objectives and materials. In fact, one interesting finding of this study is the notion of shared responsibility in evaluating. Students had the notion of shared responsibility in evaluating their course and their learning. This is in harmony with Little's (2011) argument saying that "one aspect of the individual learner autonomy in language learning is that the learner should have a role in evaluating the learning" (p. 26). When students are ready to share this responsibility with their teachers, then according to Ellis (2003), it can help them to develop the ability of taking control of their own learning. It can also help them to be prepared for goal setting, creating "reflective attitude" among learners (Little, 2011, p. 302).

\section{Table 1}

Students' views of their own and their teachers' responsibilities

\begin{tabular}{|c|c|c|c|c|c|c|}
\hline \multirow[t]{2}{*}{ Questions } & \multicolumn{2}{|c|}{$\begin{array}{l}\text { Students perceptions of } \\
\text { responsibilities in percentage }\end{array}$} & \multirow{2}{*}{$\begin{array}{l}\text { their own } \\
\text { Complete }\end{array}$} & \multicolumn{2}{|c|}{$\begin{array}{l}\text { Students' perceptions of } \\
\text { responsibilities in percentage }\end{array}$} & \multirow{2}{*}{$\begin{array}{l}\text { ir teachers' } \\
\text { Complete } \\
\end{array}$} \\
\hline & Not/A little & Some & & Not/A little & Some & \\
\hline $\begin{array}{l}\text { Make sure you make } \\
\text { progress during lessons }\end{array}$ & 22.60 & 23.30 & 54.10 & 30.10 & 26.30 & 43.60 \\
\hline $\begin{array}{l}\text { 2. Make sure you make } \\
\text { progress outside class }\end{array}$ & 25.60 & 13.50 & 60.90 & 54.10 & 21.80 & 24.1 \\
\hline $\begin{array}{l}\text { 3. Stimulate your interest in } \\
\text { learning English }\end{array}$ & 20.30 & 24.10 & 55.60 & 32.30 & 23.30 & 44.40 \\
\hline $\begin{array}{l}\text { 4. Identify your weaknesses } \\
\text { in English }\end{array}$ & 23.30 & 15.00 & 61.70 & 41.40 & 18.80 & 39.80 \\
\hline 5. Make you work harder & 13.50 & 15.80 & 70.70 & 38.80 & 27.80 & 33.80 \\
\hline $\begin{array}{l}\text { 6. Decide the objectives of } \\
\text { your English course }\end{array}$ & 38.30 & 21.80 & 39.80 & 24.10 & 21.80 & 54.10 \\
\hline $\begin{array}{l}\text { 7. Decide what you should } \\
\text { learn next in your English } \\
\text { lessons }\end{array}$ & 28.60 & 28.60 & 36.80 & 26.30 & 23.30 & 50.40 \\
\hline $\begin{array}{l}\text { 8. Choose what activities to } \\
\text { use to learn English in your } \\
\text { English lessons }\end{array}$ & 35.30 & 25.60 & 39.10 & 24.80 & 22.60 & 52.60 \\
\hline $\begin{array}{l}\text { 9. Decide how long to spend } \\
\text { on each activity }\end{array}$ & 23.30 & 21.80 & 54.90 & 37.60 & 29.30 & 33.10 \\
\hline $\begin{array}{l}\text { 10. Choose what materials to } \\
\text { use to learn English in your } \\
\text { English lessons }\end{array}$ & 44.40 & 16.50 & 39.10 & 28.60 & 18.00 & 53.40 \\
\hline 11. Evaluate your learning & 27.10 & 23.30 & 49.60 & 28.60 & 20.30 & 51.10 \\
\hline 12. Evaluate your course & 30.10 & 23.30 & 46.60 & 33.10 & 19.50 & 47.40 \\
\hline $\begin{array}{l}\text { 13. Decide what you learn } \\
\text { outside class }\end{array}$ & 18.80 & 14.30 & 66.90 & 49.60 & 25.60 & 24.80 \\
\hline
\end{tabular}

This study also showed that participants considered themselves responsible for all the activities that are directly related to their learning such as ensuring to make progress outside the class, working harder, and deciding the learning activities outside the class. The results also showed that they are eager to devote time and effort to their language learning and they are ready to accept some aspects of responsibilities.

There is another point that should be considered. As far as the participants of this research study are law major students at university level studying English for specific purposes, so they have enough knowledge in their subject matter area and more interested in taking responsibility for their own learning. They said that they had the ability to choose their objectives, so teachers can provide this opportunity for the students by using learner-centered methodology and specifically, process syllabus. As Pishghadam and Navari (2010) showed Iranian language learners' perceptions of language education in both formal and informal contexts and concluded that they mostly expressed their positive views towards learner-centered instruction through metaphors such as: "friend, comedian, artist" for their teachers and metaphors such as: "friend, team member, child, and partner" for themselves (p. 182). In his division of autonomy into different subsections, Macaro (1997) argued that there are three kinds of autonomy: (1) autonomy of language competence, (2) autonomy of language learning competence, and (3) autonomy of choice and action. He believed that learners, especially adults and adolescents "need to be given the opportunity to develop autonomy of choice" (p. 171). They need to perceive the short-term and long-term language learning objectives and perceive the materials necessary for achieving those objectives. 


\subsection{Iranian students' views of decision making ability}

The second section of the Learner Autonomy Questionnaire assessed the students' views of their decision making ability to learn language autonomously. The questionnaire covered 11 items and participants ranked their responses on a five-point Likert scale that goes from 0 (very poor) to 5 (very good). Table 2 presents the percentages of answers related to each item. For the ease of interpretation, "very poor" and "poor" categories were considered in a negative category whereas "very good" and "good" categories into one positive category have been combined.

Most of the items: $14,15,16,18,19,23$, and 24 showed students had an average level of ability to learn language autonomously. For example, for item 14 (choosing learning objectives in class) $54.9 \%$ of the respondents said that they considered themselves almost capable of choosing learning objectives in class. For items 17, 20, and 22 students said that they have "good/very good" ability to decide on their own. These items refer to "(choosing learning objectives outside the class, evaluating learning, and identifying their weaknesses in English)". Only for item 21 (evaluating their course) $39.8 \%$ of respondents revealed that they had "poor/very poor" ability to evaluate their course. But they did not consider themselves capable of doing this. For item 17 "choosing learning objectives outside the class", the participants said that they had "good/very good" ability to do this whereas this item associates with item 13 in responsibility section, "deciding what to learn outside the class" in which the students assigned this responsibility to choose their learning objectives outside the class for themselves, it means they want to practice English at their own pace. The results showed that the students were ready to accept the responsibility of deciding their objectives outside the class and they also considered themselves capable of choosing the materials and objectives to learn English outside of the class.

\section{Table 2}

Students' views of their own abilities in learning English

\begin{tabular}{|c|c|c|c|}
\hline $\begin{array}{l}\text { Section } 2 \text { items: Students' perceptions of their own abilities in } \\
\text { learning English }\end{array}$ & Very poor/poor & $\mathrm{OK}$ & Very good/good \\
\hline 14.Choosing learning activities in class & 24.80 & 54.90 & 20.30 \\
\hline 15.Choosing learning activities outside class & 36.80 & 39.80 & 23.30 \\
\hline 16.Choosing learning objectives in class & 24.80 & 38.30 & 36.80 \\
\hline 17. Choosing learning objectives outside class & 29.30 & 32.30 & 38.30 \\
\hline 18. Choosing learning materials in class & 34.60 & 36.10 & 29.30 \\
\hline 19. Choosing learning materials outside class & 30.80 & 36.80 & 32.30 \\
\hline 20. Evaluating your learning & 21.80 & 34.60 & 43.60 \\
\hline 21. Evaluating your course. & 39.80 & 33.80 & 26.30 \\
\hline 22. Identifying your weaknesses in English & 13.50 & 38.30 & 48.10 \\
\hline 23. Deciding what you should learn next in your English lessons & 28.60 & 36.10 & 35.30 \\
\hline 24. Deciding how long to spend on each activity & 24.80 & 39.10 & 36.10 \\
\hline
\end{tabular}

For item 20, the students said that they had "good/very good" ability of "evaluating learning" and they shared this responsibility with their teachers. Evaluation and assessment help students to be prepared for lifelong learning and enhance students' motivation for language learning because it is one of the essential aspects of developing autonomy. The analysis of the participants' perspectives of decision making abilities showed that learners' responses clustered on the "OK" category. They only considered themselves "good/very good" at choosing learning objectives outside the class, evaluating their learning, and identifying their weaknesses. We can conclude that the participants considered themselves capable of choosing objectives outside the class, but they considered the teacher as the responsible person. Because students assign this responsibility normally to their teachers in Iran, as Razmjou and Hadidi Tamjid (2012) stated, teachers' direct observation, involvement, and feedback give value to the class time from students' point of view.

\subsection{Iranian students' engagement inside and outside class activities}

Section three of the Learner Autonomy Questionnaire assessed the students' engagement inside and outside 
Ahmadi, R. \& Mahdavi-Zafarghandi, A.

class activities that was proposed by Chan et al. (2002) in their research study in Hong Kong Polytechnic University. The questionnaire covered 26 items: 21 items for inside class activities and 5 items for outside class activities. The students ranked their responses on a four-point Likert scale that goes from 0 (never) to 4 (often).

Table 3 presents the percentages of answers related to each item. The results indicated that the students "never" did most of the autonomous activities used in the study. Only item 27 (noting down new words and their meanings) and 47 (noting down new information) showed that the participants were "often" engaged in these activities. For item 48 (making suggestions to the teacher) $45.1 \%$ of the respondents said that they "rarely" did this. This refers to the type of interaction between the teacher and students in the classroom. The students normally listen to teachers' presentation in class and they rarely question teachers' comments. For item 35 (listening to English songs), item 40 (watching English movies), and item 50 (discussing learning problems with classmates), the respondents said that they were "sometimes" engaged in these activities. For example, item 40 (watching English movies) $27.1 \%$ of the respondents said that they were "sometimes" engaged in this activity.

\section{Table 3}

The frequency of students' engagement in autonomous inside and outside class activities

\begin{tabular}{|c|c|c|c|c|}
\hline Items & Never & Rarely & Sometimes & Often \\
\hline 25. Read grammar books on own & 29.3 & 40.6 & 21.1 & 9.0 \\
\hline 26. Done non-compulsory assignments & 36.1 & 30.1 & 21.1 & 12.8 \\
\hline 27. Noted down new words/meanings & 11.3 & 25.6 & 29.3 & 33.8 \\
\hline 28. Written English letters to pen pals & 60.9 & 22.6 & 13.5 & 3.0 \\
\hline 29. Read English notices around you & 53.4 & 30.1 & 15.0 & 1.5 \\
\hline 30. Read newspapers in English & 74.4 & 15.0 & 9.0 & 1.5 \\
\hline 31. Sent e-mails in English & 59.4 & 22.6 & 15.0 & 3.0 \\
\hline 32. Read books/magazines in English & 57.9 & 21.8 & 17.3 & 3.0 \\
\hline 33. Watched English TV programs & 24.8 & 34.6 & 22.6 & 18.0 \\
\hline 34. Listened to English radio & 58.6 & 18.8 & 17.3 & 5.3 \\
\hline 35. Listened to English songs & 23.3 & 24.8 & 26.3 & 25.6 \\
\hline 36. Talked to foreigners & 60.2 & 24.1 & 12.0 & 3.8 \\
\hline 37. talk to my friends in English & 45.1 & 36.8 & 14.3 & 3.8 \\
\hline 38. Practiced using English with friends & 49.6 & 29.3 & 14.3 & 6.8 \\
\hline 39. done grammar exercises & 38.3 & 33.1 & 21.8 & 6.8 \\
\hline 40. Watched English movies & 21.1 & 23.3 & 28.6 & 27.1 \\
\hline 41. Written diary in English & 69.9 & 20.3 & 6.8 & 3.0 \\
\hline 42. Used Internet in English & 30.1 & 30.8 & 21.1 & 18.0 \\
\hline 43. Done revision not required by the teacher & 27.1 & 35.3 & 25.6 & 12.0 \\
\hline 44. Collected texts in English & 44.4 & 25.6 & 20.3 & 9.8 \\
\hline 45. Gone to see your teacher about your work & 39.1 & 29.3 & 23.3 & 8.3 \\
\hline
\end{tabular}

Among these activities, the students said that they "never" engaged themselves in the activity expressed in item 49. It means they "never" use English to speak in class, because in the majority of cases, most of the ESP class time is devoted to reading and translating technical texts, in Persian. In general, this study revealed that they "never" did classroom autonomous activities proposed and used in this study. Although they considered themselves responsible for selecting activities outside of the class, the results showed that they were never engaged in these autonomous activities. They definitely need more guidance and support to do so.

This group of students indicated that they "often" watched movies in English or they noted down new words and new information to learn them. This is why Iranian students did not practice most of the autonomous activities used in this study. English is a subject matter in higher education rather than a skill or medium for communication and students are rarely exposed to English in real life environment. They said that they were not interested to use internet in English, that they never practiced English with their friends, and that they never read newspapers or magazines in English. We could conclude that our students need more opportunities for learning language both inside and outside of the class and lack of facilities, exposure to English are two important reasons for their disengagement in autonomous activities. 
4.4 Iranian students' views of responsibility and ability in autonomous language learning regarding their gender

The chi-square test of independence was used to find whether or not there is a relationship between students' views of responsibility and ability regarding their gender. The relationship was considered significant at $\mathrm{p}<.05$ level. The results of chi-square revealed that there was no significant difference between male and female participants in terms of responsibility and ability perceptions.

\section{Conclusion and implication}

The results of this study show that Iranian learners are ready to accept the responsibility of some aspects of their learning, but they still need the teacher to manage all classroom activities as well as choose materials and objectives. The findings also indicate that students consider their ability level as average showing that they can manage their learning. In terms of the autonomous activities the Iranian students said that they never practiced most of the autonomous activities. Kiany, Mahdavy, and Ghafar Samar (2013) conducted a research study on Iranian learners to show their motivational changes in a traditional context and concluded that "context is more in favor of extrinsic motivational forces rather than intrinsic types" (p. 12). They also indicated it is hard to develop learner autonomy in this kind of context. However, fostering autonomous language learning is unavoidable to help students to become creative and lifelong learners.

Implications arising from this study suggest that: Knowing the students' views of their responsibility and ability help material developers, teachers, and administrators to prepare programs and materials to develop autonomous behaviors among students. English is a foreign language in Iran and it is not used as the primary medium of communication, so providing opportunities such as autonomous activities proposed in this study and a shift in responsibility towards learners and learner-centered methodology would facilitate the development of autonomy in foreign language learning contexts. The results of this study also facilitate the development of resources such as self-access centers which encourage independent language learning among students.

\subsection{Suggestions for further research}

In the present study the data were gathered only form ESP students, another study can be carried out gathering data from ESP teachers. In addition, still another line of research can be conducted by collecting data through various instruments: Interview, learner diaries, and portfolios. And finally, further studies can be conducted in different contexts with different students to investigate the effect of contextual factors on the development of autonomous language learning.

\section{References:}

Aoki, N. (1999). Affect and the role of teacher in the development of learning autonomy. In J. Arnold (Ed.), Affect in language learning (pp. 142-145). Cambridge: Cambridge University Press.

Benson, P. (2006). Learner autonomy: Insider perspectives on autonomy in language teaching and learning. Dublin: Authentik.

Benson, P. (2009). Making sense of autonomy in language learning. In R. Pamberton, S. Toogood, \& A. Barfield (Eds.), Maintaining control: Autonomy and language learning (pp. 13-26). Hong Kong University Press. http://dx.doi.org/10.5790/hongkong/9789622099234.003.0002

Chan, V., Humphreys, G., \& Spratt, M. (2002). Autonomy and motivation: Which comes first? Language Teaching Research, 6(3), 245-266. http://dx.doi.org/10.1191/1362168802/r106oa

Dickinson, L. (1994). Learner autonomy: What, why, and how? In V. J. Leffa (Ed), Autonomy in language learning (pp. 2-12). Porto Alegre: Universidade/ UFRGS.

Dickinson, L. (1995). Autonomy and motivation: A literature review. System, 23(2), 165-174.

http://dx.doi.org/10.1016/0346-251X(95)00005-5 
Ahmadi, R. \& Mahdavi-Zafarghandi, A.

Ferrell, T., \& Jacobs, G. (2010). Essentials for successful English language teaching. Continuum International Publishing Group.

Hofstede, G. (1986). Cultural differences in teaching and learning. International Journal of Intercultural Relations, 10, 301-320. http://dx.doi.org/10.1016/0147-1767(86)90015-5

Hofstede, G. (2006). Dimensionalizing cultures: The Hofstede model in context. In W. J. Lonner, D. L. Dinnel S. A. Hayes, \& D. N. Sattler (Eds.), Online readings in psychology and culture. Bellingham WA: Center for Cross-Cultural Research, Western Washington University.

Holec, H. (1981). Autonomy in foreign language learning. Oxford: Program Press.

Kashefian -Naini, S. (2002). An investigation into college EFL learners' beliefs demonstrating their predispositions towards learner autonomy. Unpublished masteral thesis, Shiraz University, Shiraz, Iran.

Kiany, Gh. R., Mahdavy, B., \& Ghafar S. (2013). Motivational changes of learners in a traditional context of English education: A case study of high school students in Iran. International Journal of Research Studies in language Learning, 2(1), 3-16. http://dx.doi.org/10.5861/ijrsll.2012.92

Little, D. (1999). The European language portfolio and self-assessment. Strasbourg: Council of Europe.

Little, D. (2004). Constructing a theory of learner autonomy: Some steps along the way. In K. Makinen, P. Kaikkonen, \& V. Kohonen (Eds.), Future perspectives in foreign language education (pp. 15-25). Oulu, Finland: Publications of the Faculty of Education.

Little, D. (2007). Reconstructing learner and teacher autonomy in language education. In A. Barfield S. Brown (Eds.), Reconstructing autonomy in language education: Inquiry and innovation (pp.1-13). Basingstoke: Palgrave: Macmillan.

Little, D. (2011). The common European framework of reference for languages: A research agenda. Language Teaching, 44(3), 381-393. http://dx.doi.org/10.1017/S0261444811000097

Littlewood, W. (1999). Defining and developing autonomy in East Asian contexts. Applied Linguistics, 20(1), 71-94. http://dx.doi.org/10.1093/applin/20.1.71

Macaro, E. (1997). Target language, collaborative learning and autonomy: Modern language in practice. Clevedon, Philadelphia, USA: Multilingual Matters Ltd.

Pishghadam, R., \& Navari, S. (2010). Examining Iranian language learners' perceptions of language education in formal and informal contexts. The Modern Journal of Applied Linguistics, 2(1), 171-185.

Pishghadam, R., \& Naji Meidani, E. (2011). Culture and education: Bringing to light the views of Iranian students of English, French, and Arabic majors towards learning and teaching. International Journal of Innovative Interdisciplinary Research, 1, 21-35.

Smith, R. (2002). Autonomy, context, and appropriate methodology. In F. Vieira, M. A. Moreira, I. Barbosa, \& M. Paiva (Eds.), Pedagogy for autonomy and English learning: Proceedings of the $1^{\text {st }}$ conference of the working group-pedagogy for autonomy. University of Minho, $11^{\text {th }}-14^{\text {th }}$ March. Barga: University of Minho, 13-23.

Zohrabi, M. (2011). Enhancing learner autonomy through reciprocal approach to curriculum development. English language Teaching, 4(3), 120-127. http://dx.doi.org/10.5539/elt.v4n3p120 